\title{
Time Operated Electrical Appliance Controlling Systems by Using Microcontroller
}

\author{
Awadallah Sulieman Rahama ${ }^{1}$, Dr. Dalia Mahmoud ${ }^{2}$ \\ ${ }^{1,2}$ Department of Control, Faculty of Engineering, Al Neelain University, Khartoum, Sudan, 2016
}

\begin{abstract}
Time operated electrical appliance controlling system is a reliable circuit that takes over the task of switch on/off the electrical devices with respect to time. The operator may not be at place and may be somewhere in a different place and if the necessity arises to control these different appliances there must be some source to control and monitor the different appliances. This idea replaces the Manual Switching to automatic switching. The devices at home like electrical light, electric fan, air conditioners are needed to control so using the microcontroller of this process and there are two relays to control in buzzer and fan at a certain time. When this time equals to the programmed time, then the corresponding device is switched $O N$ and at the end of time the device is switched OFF and the switching time can be edited at any Time using the keypad and the instructions are displayed on LCD display
\end{abstract}

Keywords: LCD, LM7805, AC, DC.

\section{Introduction}

With advancement of technology things are becoming simpler and easier for us and automation is the use of control systems and information technologies to reduce the need for human work in the production of goods and services. The main purpose of this work is to design and construct a micro computer based system to control electric appliances such as light, fan, buzzer, etc. The most important problems faced are the misusage of electricity and its loss. Sometimes due to carelessness of the persons lamps or fans are left $\mathrm{ON}$ which results in wastage of electricity. The design helps to finish all these problems [2]. Microcontroller is used to monitor the actions of all other devices and to control the entire set of operations and electronic clocks have predominately replaced the mechanical clocks. They are much reliable, accurate and there are two types of electronic clocks they are analog clock and digital clock but digital clocks are more common and independent of external source. It would be needed the controlled devices and implementation of software for microcontroller control system because the hardware device cannot do any desired task to execute. High speed microcontrollers are widely used in portable equipment. The microcontroller based digital clock is constructed with software program is written with $\mathrm{C}$ program language. To enable the system (hardware) running, the microcontroller needs to be programmed first. Because the microcontroller operating as the control panel that would control all the operation in the display system. The output "ON" and "OFF" of the appliances also depends on the programming. The software development process for the whole design can be divided into two main sections. The first section is the development process in programming the $\mathrm{C}$ language for the microcontroller and the second section is the development process for the Graphic User Interface design for the system. In order to program the microcontroller works must be controlling in microcontroller is only the feature of the clock. The system works on an in-built electronic processing and data storage system that has the ability to make intelligent decisions on the control and regulation of appliances in specified area [1].

\section{Materials and Methods}

The system administrator of the Time Operated Electrical Appliance Control system has the ability to add or delete a different appliance and its operations and also the system administrator can add or delete user. The user can give instructions to existing device, get the status of a device and set the operation of a different appliance [5]. Microcontrollers make it economical to electronically control many more processes. Use case diagrams are central to modeling the output of the system and it shows a set of use cases and their relationships. The following figure shows the use case diagram of the Time Operated Electrical Appliance Control system.

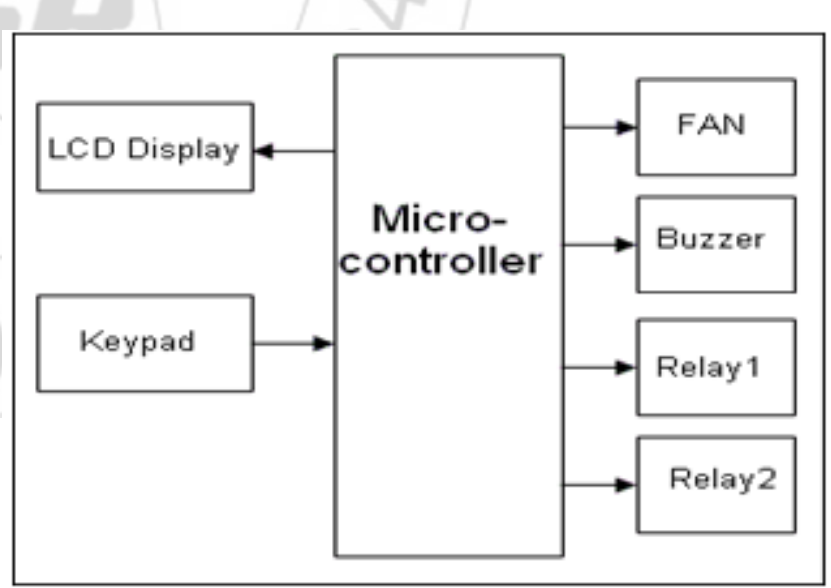

Figure 1: Block diagram

The circuit has a two relays to control in a fan and buzzer and it has keypad to enter the orders or parameters and it has a LCD to display the instructions and it has power supply circuit to convert from AC to DC and a Microcontroller is used in automatically controlled devices, the system works when microcontroller is on. When this time equals to the programmed time, then the corresponding device is switched $\mathrm{ON}$ and at the end of time the device is switched OFF and first buzzer works for period of time and then stop as a sign that the fan will run and then the fan operate for a period of time. 


\section{International Journal of Science and Research (IJSR) \\ ISSN (Online): 2319-7064}

Index Copernicus Value (2013): 6.14 | Impact Factor (2015): 6.391

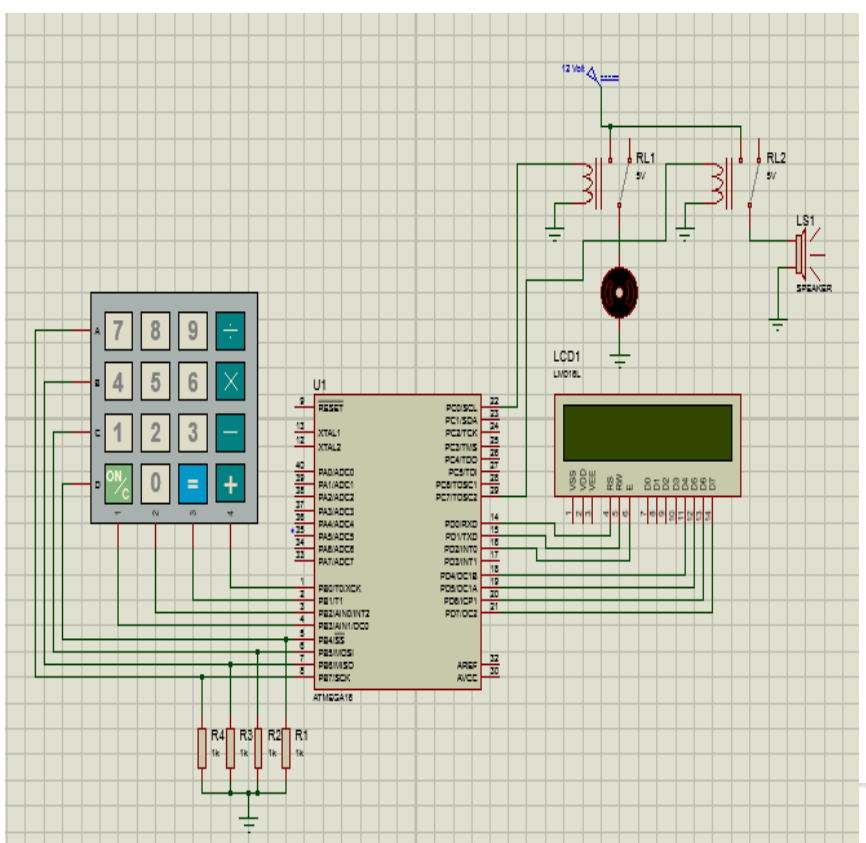

Figure 2: Circuit diagram

Microcontroller is used to supervise of all other devices and to control the entire set of procedures. Each device will have an on-time and off-time. So the kit will daily switch on the device at the on-time and switch it 0ff when the real time is same to the off time of the device. The appliance is switched on when the user time and real clock time is equal. There are two timings, one is "on time" and the second is "off time" [3]. In this design used 12 volts transformer for continuous power supply. Because of this can have continuous power, hence use it. Otherwise if use a battery sometimes the total currents will loss so that's way using AC Transformer. AC transformer is giving the input to Bridge Rectifier. Bridge Rectifier converts $\mathrm{AC}$ to $\mathrm{DC}$ and after that using one filter capacitors 470 and $0.1 \mathrm{uf} / 25 \mathrm{v}$ electrolytic capacitor and connecting this capacitor in parallel section. The main purpose of this capacitor is if there are any alternate peaks we need to reduce that peaks nothing but filtering those ripples and after that using LM7805 Regulator Most digital logic circuits and processors need a 5 volt power supply, to use these parts need to build a regulated 5 volt source. Make a 5 volt power supply, The LM7805 is simple to use. First connect the positive lead of unregulated DC power supply input pin, connect the negative lead to the Common pin and then when turn on the power, get a 5 volt supply from the Output pin [6].

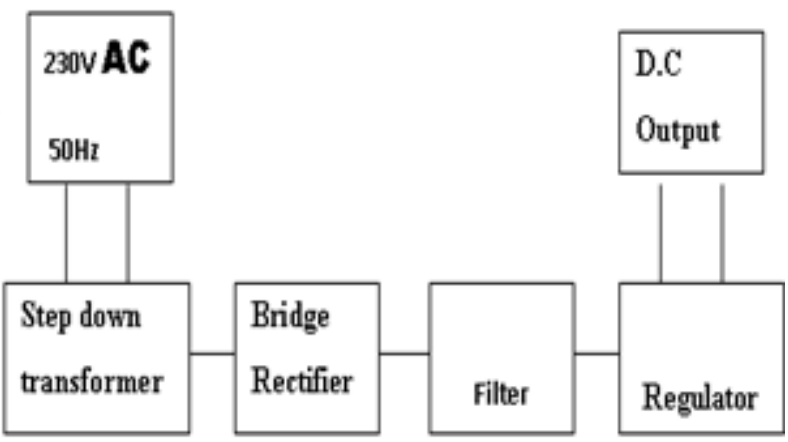

Figure 3: block diagram for power supply circuit
Initial stage of every electronic circuit is power supply system which provides required power to drive the whole system. The specification of power supply depends on the power requirement and this requirement is determined by its rating. The main components used in supply system are:
1) Transformer
2) Rectifier
3) Input filter
4) Regulator
5) Output filter
6) Output indication
- Transformer

The main source of power supply is a transformer and the maximum output power of power supply is dependent on maximum output power of transformer and determine power from its current and voltage rating.

\section{- Rectifier}

Rectifier is a circuit which is used to convert ac to dc and every electronic circuit requires a dc power supply for rectification and this circuit we have used four diodes.

- Input filter

After rectification we obtain dc supply from ac but it is not pure dc it may have some ac ripples and to reduce these ripples we use filters and it comprises of two filters such as low frequency ripple filter and high frequency ripple filter. To reduce low frequency ripples we use electrolytic capacitor and the voltage rating of capacitor must be double from incoming dc supply. It blocks $\mathrm{dc}$ and passes ripples to ground.

- Regulator

Regulator is a device which provides constant output voltage with varying input voltage. There are two types of regulators:

- Fixed voltage regulator

- Adjustable regulator

In this case it uses a fixed voltage regulator LM7805 last two digits signify output voltage. The voltage in this system is $5 \mathrm{~V}$ that is why we have used 7805 regulator which provides $5 \mathrm{~V}$ from $12 \mathrm{~V} \mathrm{dc}$ and this supply is for the microcontroller, display and relay unit. The microcontroller requires 5 volt supply to perform any desired task [4].

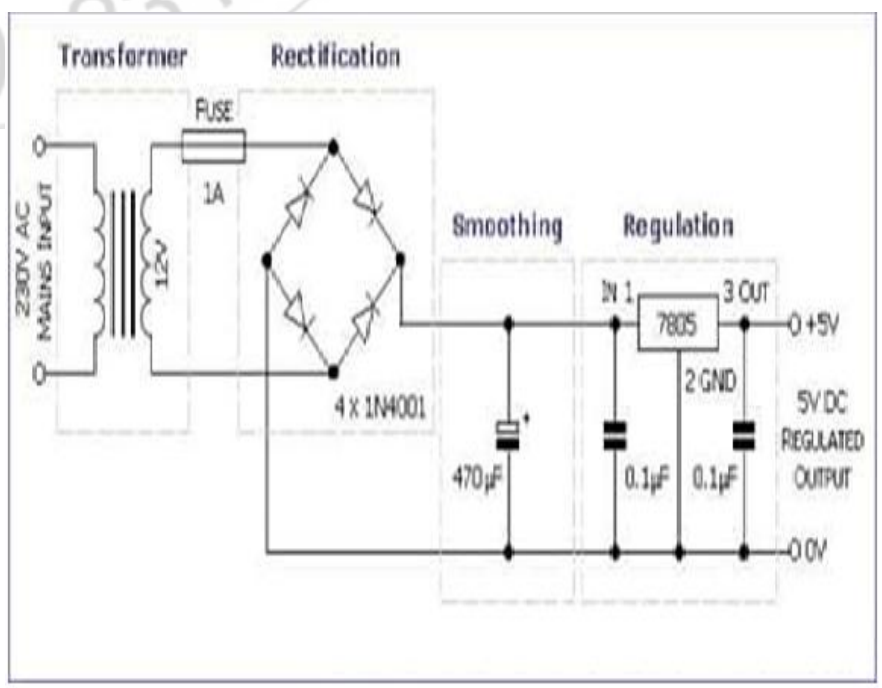

Figure 4: Power supply circuit 


\section{International Journal of Science and Research (IJSR) \\ ISSN (Online): 2319-7064}

Index Copernicus Value (2013): 6.14 | Impact Factor (2015): 6.391

\section{Results and discussions}

The electrical devices connected in the factory, home or any place, consume electrical power, and there is an absolute necessity of saving of power as per present day situations. So it is necessary to control electrical devices more effectively and efficiently at anytime from anywhere. So this project is built for the sole purpose of efficient control of electrical appliances. The operation of the circuit depends on the time and can be used in different appliances to control the device based in different time. This system can be used in industrial applications and home. This design reduces the human efforts or human interaction and makes life very easy without compromising on the efficiency of appliances and using this system one con also save time and thus it can works independently as an automated circuit and it can monitor some hazardous and Real time implementation and deployment of the system has a huge potential of minimizing energy wastage in various appliances such as a domestic and industrial electrical applications.

\section{Conclusion}

The main aim of this paper is to design and employ of power saving in general public places like home, factory etc. Generally the factory consists of so many numbers of electrical and electronic devices or equipments. To control and monitor all these equipments or appliances we need a person or controlling system. In this paper we are presenting the working of smart power controlling and saving in home, factory etc, by using an electronic circuit in an easy way without having human being. This paper describes the complete working of electrical and electronic devices with automatic control and also power saving in home, factory. Time operated electrical appliance controlling system is a locally customized device capable of switching electrical devices with respect to time and can be used for different appliances such as factories and homes and it use purposely to prevent electrical hazard also generate post operation of the attached devices and the prototype of Time Operated Electrical Appliance Control System Based has a two relay to control in a fan and buzzer and it has keypad to input parameters and a LCD to display commands and a Microcontroller is used in automatically controlled devices is fully ready and functional.

\section{References}

[1] "8051 and embedded system" by Mazidi and Mazidi

[2] All datasheets from www.datasheetcatalog.com

[3] About AT89s8252 from www.atmel.com And www.triindia.co.in

[4] William C. Mann (ed.) Smart technology for aging, disability and independence: the state of the science, John Wiley and Sons, 2005 0- 471-69694-3, pp. 34-66

[5] Malik Sikandar, H. K., Aihab K., Erum S. (2009). SMS Based Wireless Home Appliance Control System (HACS) for Automating Appliances and Security. Issues in Informing Science and Information Technology, 6, 887--894.
[6] Ahmad Kamil bin Abdul Rahman, "Bluetooth Message Display". Universiti Teknologi Malaysia: Thesis Bachelor, 2007

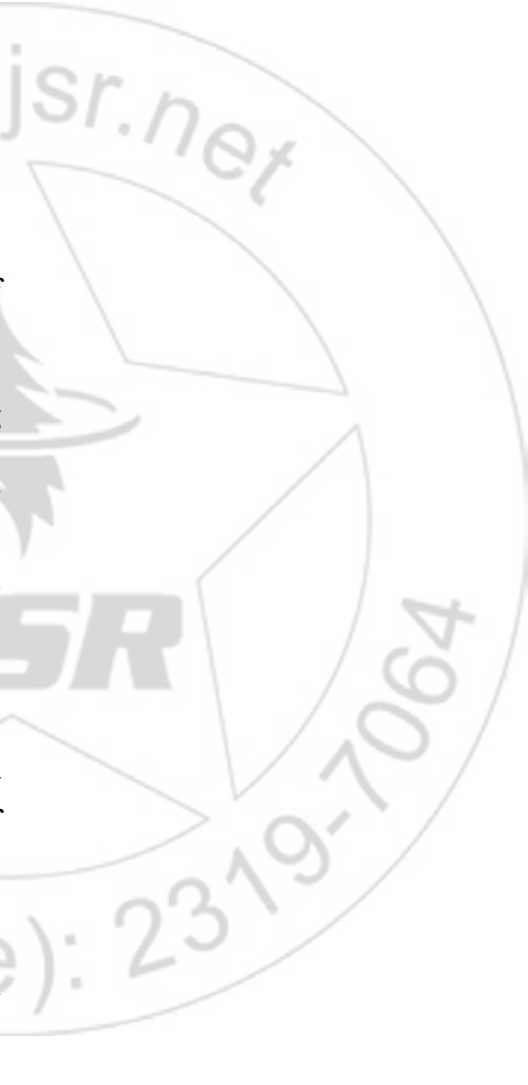

